\title{
Improving the Student Competency of the "Modeling and Computation Process" Course by Using Open Source Application.
}

\author{
Setia Budi Sasongko ${ }^{1, *}$, and Luqman Buchori ${ }^{2}$. \\ ${ }^{1,2}$ Computational Process Laboratory, Department of Chemical Engineering, Faculty of Engineering, Diponegoro University, \\ Indonesia
}

\begin{abstract}
One of the student outcome based on ABET is the ability to use the techniques, skills, and modern engineering tools (in this case is engineering software) necessary for engineering practice. The problem is how the process of student centered learning so that the learning outcome of the "Modeling and computation process" subject can be achieved especially analysis process using modern engineering software. The first problem is commercial software applications have limitations due to high prices and limited amounts and usage time. The second problem is pasive student caused of one-way learning. The first problem is solve by utilisation of the open source software, that is "scilab" and "COCO". The blended learning method is used to minimize the second problem, that is combination of face-to-face learning in the class, distance learning which use the "edmodo", and accompaniment learning by senior student in the computation laboratory. The results of the active learning are increasing the ability of the student to apply equipment design and process system, improving soft skill outcome such as team work, communication, time management, thinking criticaly and analysing effectively.
\end{abstract}

\section{Background}

The change of education from lecturer-centered learning toward student-centered learning is not easy. One way to improve active student is to use software engineering applications in the learning process. This is in line with one of ABET student outcomes, that is the ability to use the techniques, skills, and modern engineering tools (in this case is engineering software) necessary for engineering practice.

The first problem to meet previous performance indicator is commercial software applications have limitations due to high prices and limited amounts and usage time. The second problem is generally learning process based on the lecture activity or one-way learning.

\section{Learning Methodology}

In the Information Age, the chemical engineering education should shift to the use of industrial software so that students will be easy to apply theory of basic chemical engineering to the design of chemical industry. The limitation of the commercial software (first problem) can be overcome by using open source software that is scilab and COCO. The Scilab (Matlablike) is free open-source software for the numerical computation and scientific applications[1]. COCO (CAPE-OPEN to CAPE-OPEN) is a free of charge CAPE-OPEN (Computer-Aided Process Engineering) compliant steady state simulation environment [2]. The COCO is developed and maintained by AmsterCHEM which is collection of software component consist of four main component there are COFE the flow-sheeting engine, TEA (Thermodynamic for Engineering Application), COUSCOUS (collection of unit operations) and CORN (reaction numerical package).

The blended learning is applied in this subject to overcome teaching centered learning (second problem). Blended learning (figure 1) means the combination of three learning methods that are first face-to-face learning in the class, second distance learning which use the "edmodo", and accompaniment learning by senior student in the computation laboratory. The Edmodo is teaching tool modeled which designed for teacher/student interaction with emphasis on communication, assignment sharing [3].

The "Modeling and computation process" subject in the Chemical Engineering Department, Diponegoro University is taken as an active learning sample. The

Corresponding author: sbudisas@live.undip.ac.id 
learning outcomes of this subject is the student will have an ability to apply engineering fundamental using computer programming or simulation.

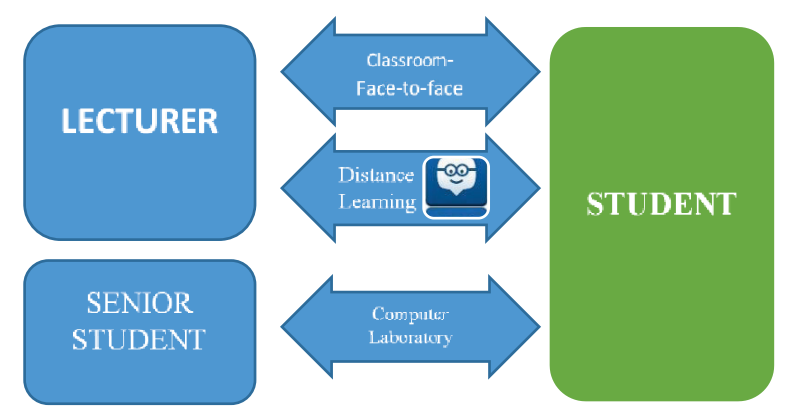

Fig. 1. Blended learning method

In the classroom (face-to-face learning), the learning process implemented tutorial applied program directly, because most students bring their laptops. Requirement specification of the "Scilab" and "COCO" are not high, therefore notebook can be used for the learning process in the class. Lecturer gives the simple problem, than student solve it under lecturer supervision. In this case, learning process consist of small group discussion, problem based learning. Application of Information Technology (IT) in education will improve three C's: Computing, Communication and Collaboration [4]. Therefore, the outcomes of this process are team work, communication, and critical thinking. In general, the relationship between open source software with the learning process can be seen in Figure 2.

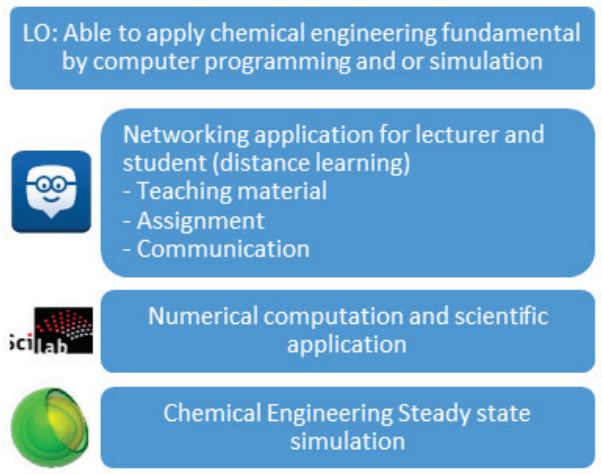

Fig. 2. Relationship between learning outcome (LO) with open source software in the "Modeling and computation process" subject.

Both software (COCO and scilab) in the learning process have different approach. COCO is used to study the overall process system (black-box system). Scilab is used to study each unit (section) in detail. In this case, students in a group get the assignment to design the reactor using scilab. Every group has a different problems, as shown in table 1. Each alphabet has a meaning as shown in table 2 .
Table 1. Several type of assignment

\begin{tabular}{|c|c|c|c|}
\hline Group & Assignment & Group & Assignment \\
\hline 1 & A C E G I & 7 & A C E H I \\
\hline 2 & B C E G I & 8 & B C E H I \\
\hline 3 & A D E G I & 9 & A D E H I \\
\hline 4 & B D E G I & 10 & B D E H I \\
\hline 5 & A C F G I & 11 & A C F H I \\
\hline 6 & B C F G I & 12 & B C F H I \\
\hline
\end{tabular}

Table 2. Classification code for the group assignment

\begin{tabular}{|c|c|c|c|}
\hline No. & $\begin{array}{c}\text { Classification, } \\
\text { based on }\end{array}$ & \multicolumn{2}{|c|}{ Classification code } \\
\hline \multirow[b]{2}{*}{1} & \multirow[b]{2}{*}{ Type of reactor } & $\mathbf{A}$ & B \\
\hline & & $\begin{array}{c}\text { CSTR } \\
\frac{X}{V}=\frac{-r_{A}}{F_{A o}}\end{array}$ & $\begin{array}{c}\text { PFR } \\
\frac{d X}{d V}=\frac{-r_{A}}{F_{A o}}\end{array}$ \\
\hline \multirow[b]{2}{*}{2} & \multirow{2}{*}{$\begin{array}{l}\text { Influence of } \\
\text { heat to the } \\
\text { environment }\end{array}$} & $\mathrm{C}$ & D \\
\hline & & $\begin{array}{c}\text { Adiabatic } \\
Q=0\end{array}$ & $\begin{array}{c}\text { Non adiabatic } \\
Q \neq 0\end{array}$ \\
\hline \multirow[b]{2}{*}{3} & \multirow[b]{2}{*}{$\begin{array}{l}\text { Heat of } \\
\text { reaction }\end{array}$} & $\mathbf{E}$ & $\mathbf{F}$ \\
\hline & & $\begin{array}{c}\text { Exothermic } \\
\Delta \mathrm{H}_{\mathrm{R}}=-\end{array}$ & $\begin{array}{c}\text { Endodermis } \\
\Delta \mathrm{H}_{\mathrm{R}}=+\end{array}$ \\
\hline \multirow[b]{2}{*}{4} & \multirow[b]{2}{*}{ Equilibrium } & G & H \\
\hline & & $\begin{array}{c}\text { Irreversible } \\
\qquad A \rightarrow B\end{array}$ & $\begin{array}{c}\text { Reversible } \\
A \Leftrightarrow B\end{array}$ \\
\hline \multirow[b]{2}{*}{5} & \multirow[b]{2}{*}{$\begin{array}{l}\text { Molecular of } \\
\text { reactant }\end{array}$} & I & $\mathbf{J}$ \\
\hline & & $\begin{array}{c}\text { Mono } \\
\text { molecular } \\
A \rightarrow \mathrm{D}\end{array}$ & $\begin{array}{l}\text { Bimolecular } \\
A+B \rightarrow \mathrm{D}\end{array}$ \\
\hline
\end{tabular}

After completing the assignment, students can work in teams, communicate, share knowledge, and be more creative.

The development of a process system (imitating Coco) by merging excel as a data base with Scilab GUI (Graphical User Interface) is also done by the students as shown in Figure 3.

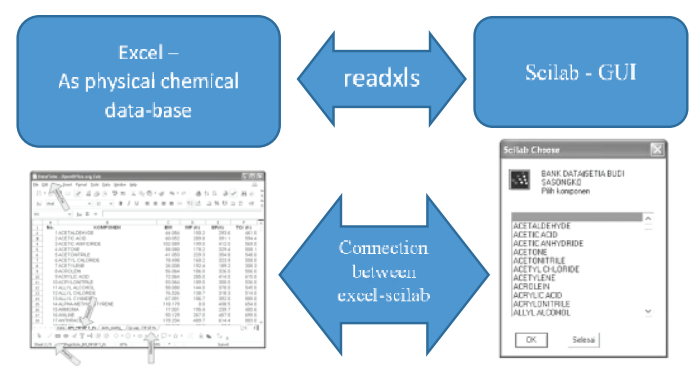

Fig. 3. Relationship between excel with scilab (GUI) to replicate property package in $\mathrm{COCO}$ simulator (Hysyslike).

Coco is used to develop the design of chemical plants as shown in Figure 4. 


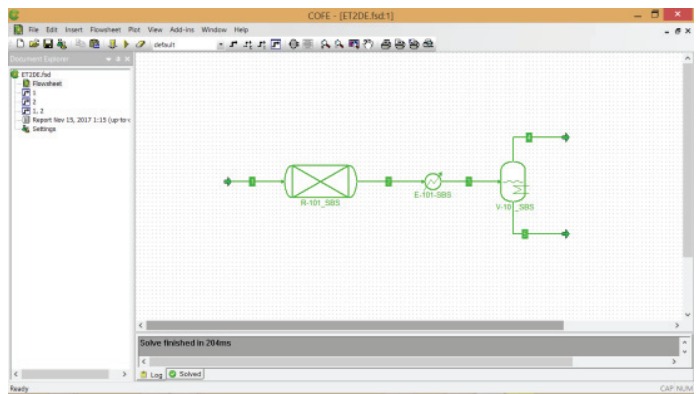

Fig. 4. Simple simulation using Coco

\section{Conclusion}

The development of learning based on the information technology will improve the student learning outcomes, both knowledge, skills and affective. Open source software can overcome the limitations of expensive commercial software without reducing the function of learning and software development.

\section{References}

1. Campbell S.L. Chancelier J, Modeling and Simulation in Scilab/Scicos, Available at: http://www.cse.iitb.ac.in/ nitinwagmode/seminar/sc icos_paper/book.pdf.

2. www.cocosimulator.org

3. www.edmodo.com

4. Edgar T., Chemical Engineering Education and the Three C's: Computing, Communication, and Collaboration. AIChE Annual Meeting, LA, Available at: http://cache.org/site/news_stand/fall00/ fall2000_chemengedu.pdf [Accessed December 14, 2014] 